\title{
Surge Wave Propagation in a Common Tailrace Channel for Two Large Pumped-Storage Plants
}

\author{
Stéphane Terrier, M.Sc. ${ }^{1}$; Martin Bieri, Ph.D. ${ }^{2}$; Giovanni De Cesare, Ph.D. ${ }^{3}$; \\ and Anton J. Schleiss, Ph.D. ${ }^{4}$
}

\begin{abstract}
Sudden starting and stopping of turbines and pumps lead to highly unsteady flow in tailrace channels of hydropower plants (HPP). Submergence of Pelton turbines and air entrainment in pumps due to surge waves must be avoided by technical measures. The existing 240 MW Veytaux pumped-storage plant in Switzerland will be enlarged by a new powerhouse adding another 240 MW, using the same tailrace channel and intake. Therefore, surge waves, induced by the two combined HPPs' operation, were investigated using a physical model. For its validation, the flow behavior of the present scheme was tested and compared to prototype measurements. The enhanced scheme was investigated to analyze critical scenarios, to optimize the plant operation rules, and to define its limits. The effect of the layout on wave reflection in pump mode is highlighted and compared to theoretical approaches. DOI: 10.1061/(ASCE)HY.1943-7900.0000809. (C) 2014 American Society of Civil Engineers.
\end{abstract}

Author keywords: Pumped-storage plant; Physical modeling; Surge wave; Tailrace channel.

\section{Introduction}

Surge waves appear as sudden variations in the height of the water level due to a change in discharge that travels in an open channel. Undular bores and secondary waves play an important role in the design of hydraulic structures as tailrace and headrace channels of hydropower plants (HPPs). Sudden starting and stopping of turbines or pumps in normal or emergency conditions determine the layout of the powerhouse as well as its supply channels. Therefore, already in the early 20th century, surge waves were investigated experimentally by Favre (1935) in order to define the development of a wave train induced by the rapid opening or closing of a gate. Since then, several studies have been conducted to understand and simulate highly unsteady nonuniform flow conditions. Despite this knowledge acquisition, dealing with surge waves and their interaction is still a challenge for HPP designers for both new and enhancement projects.

Currently, and despite energy losses of some 20\% (Swiss Federal Office of Energy (SFOE) 2008), hydraulic pumped-storage is the only practical solution to store large quantities of volatile energy. Switzerland has geographical, topographical, and hydrological

${ }^{1}$ Research Associate, Laboratory of Hydraulic Constructions (LCH), Ecole Polytechnique Fédérale de Lausanne (EPFL), CH-1015 Lausanne, Switzerland (corresponding author). E-mail: stephane.terrier@epfl.ch

${ }^{2}$ Senior Engineer, Pöyry Switzerland, Hardturmstrasse 161, P.O.Box, CH-8037 Zurich, Switzerland; formerly, Laboratory of Hydraulic Constructions, Ecole Polytechnique Fédérale de Lausanne (EPFL), CH-1015 Lausanne, Switzerland. E-mail: martin.bieri@poyry.com

${ }^{3}$ Senior Research Associate, Laboratory of Hydraulic Constructions (LCH), Ecole Polytechnique Fédérale de Lausanne (EPFL), CH-1015 Lausanne, Switzerland. E-mail: giovanni.decesare@epfl.ch

${ }^{4}$ Professor, Laboratory of Hydraulic Constructions (LCH), Ecole Polytechnique Fédérale de Lausanne (EPFL), CH-1015 Lausanne, Switzerland. E-mail: anton.schleiss@epfl.ch

Note. This manuscript was submitted on December 21, 2012; approved on July 19, 2013; published online on July 25, 2013. Discussion period open until July 1, 2014; separate discussions must be submitted for individual papers. This paper is part of the Journal of Hydraulic Engineering, Vol. 140, No. 2, February 1, 2014. (C) ASCE, ISSN 0733-9429/2014/2-218$225 / \$ 25.00$. advantages for the development of high head pumped-storage supplying and absorbing energy to and from the European grid. It already has a long tradition of pumped-storage plants.

In January 2011, the total installed capacity of HPPs greater than $300 \mathrm{KW}$ amounted to $14,450 \mathrm{MW}$ in Switzerland; some 1,750 MW are installed for pumping (SFOE 2011). Three upgrading projects are currently under construction: the 1,000 MW Linth-Limmern, the 900 MW Nant-de-Drance, and the 240 MW Hongrin-Léman pumped-storage schemes.

The existing Hongrin-Léman pumped-storage scheme, located in western Switzerland, commissioned in 1970 and operated by Forces Motrices Hongrin-Léman (FMHL), exploits a maximum head of $878 \mathrm{~m}$ between the upper Hongrin Reservoir [1255 m above sea level (a.s.1.)] and Lake Geneva (372 m a.s.1.) at the Veytaux 1 underground powerhouse, which contains four pumpturbine units with a total installed power of 240 MW. During off-peak periods, water from Lake Geneva is pumped at a maximum rate of $24 \mathrm{~m}^{3} / \mathrm{s}$ to be turbined during periods of high electricity demand with a discharge of up to $33 \mathrm{~m}^{3} / \mathrm{s}$. The Hongrin Reservoir has a usable volume of $53.2 \times 10^{6} \mathrm{~m}^{3}$.

The objective of the FMHL + enhancement project is to double the installed plant capacity by constructing a new underground cavern adjacent to the existing one (Fig. 1). Two additional pumpturbine units of $120 \mathrm{MW}$ each will be installed. The increased flexibility will allow the plant to play an important role in on-demand electricity, supplying electricity to western Switzerland, and to meet the growing demand for balancing energy, which is mainly due to the extension of renewable energies, such as wind and solar, in Europe and Switzerland.

The new plant will mainly use the existing upstream (headrace tunnel and penstock) and downstream (tailrace channel and intake/ outlet work) hydraulic system. Therefore, special attention must be paid to the combined operation of the two plants.

This paper presents the results of surge wave experiments in an open tailrace channel. The main goal of the study is to discuss the influence of the HPP layout as well as its operation on surge wave propagation and reflection in pump mode. 


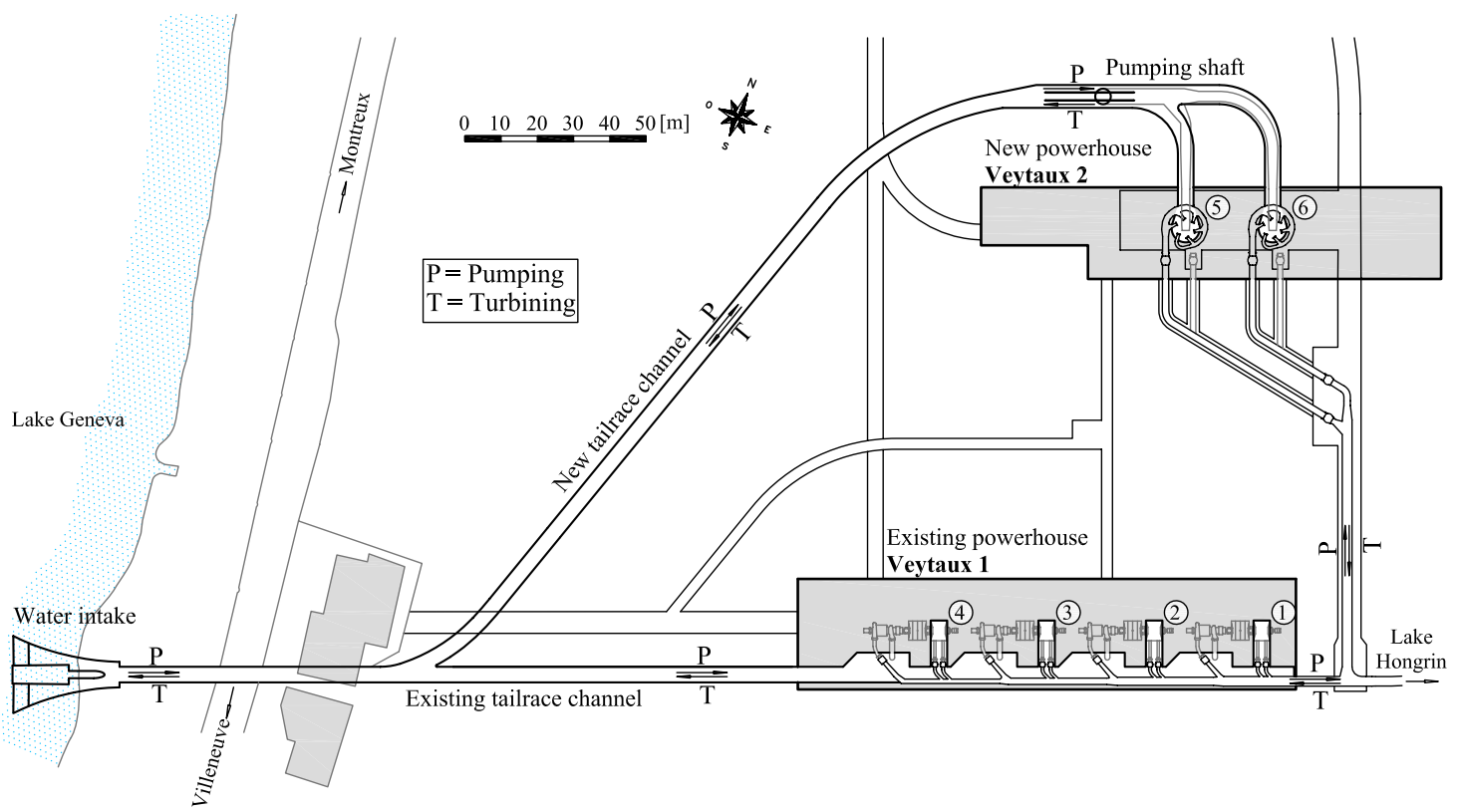

Fig. 1. Schematic drawing of existing and new Veytaux underground pump-turbine plants

\section{Unsteady Open Channel Flow}

In unsteady nonuniform flow conditions, hydraulic parameters, such as discharge, velocity, and flow depth, are time and space dependent. Sudden starting and stopping of turbines or pumps of HPPs can induce such conditions (Meile et al. 2011). Unsteady nonuniform flow can be gradually or rapidly varied. The latter is characterized by a suddenly changed free surface with high curvature called a surge wave (translation wave, gravity wave). Therefore, the assumption of hydrostatic pressure might not be valid in certain channel reaches. Four different types of surge waves are defined (Favre 1935; Chow 1959): positive surge wave advancing downstream, positive surge wave advancing upstream, negative surge wave retreating downstream, and negative surge wave retreating upstream.

In a horizontal, rectangular channel of width $B$ without friction, having a base flow $Q_{1}=U_{1} \cdot B \cdot h_{1}$, an increase in the discharge at the upstream channel border always leads to a positive surge with a steep front. The water surface discontinuity, called a positive surge

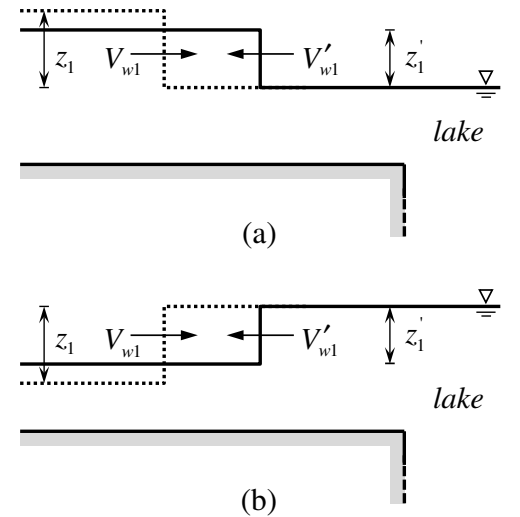

Fig. 2. Partial reflection of positive (a) and negative (b) surge at entrance of lake, where $V_{w}$ is absolute surge wave celerity observed by a stationary observer and $z$ surge height; index ' refers to postreflection conditions from upstream, travels downstream with an absolute celerity $V_{w}$ of the surge wave front:

$$
V_{w}=U_{1}+\sqrt{g h_{1}} \cdot \sqrt{\frac{h_{2}}{2 h_{1}}\left(1+\frac{h_{2}}{h_{1}}\right)}
$$

where $U=$ mean flow velocity and $h=$ flow depth. Indices 1 and 2 refer to the pre- and postsurge conditions. The other three types of surge waves are defined analogously (Henderson 1966).

In natural channels or rivers, where the channel slope and friction have to be considered, the propagation of a surge depends on
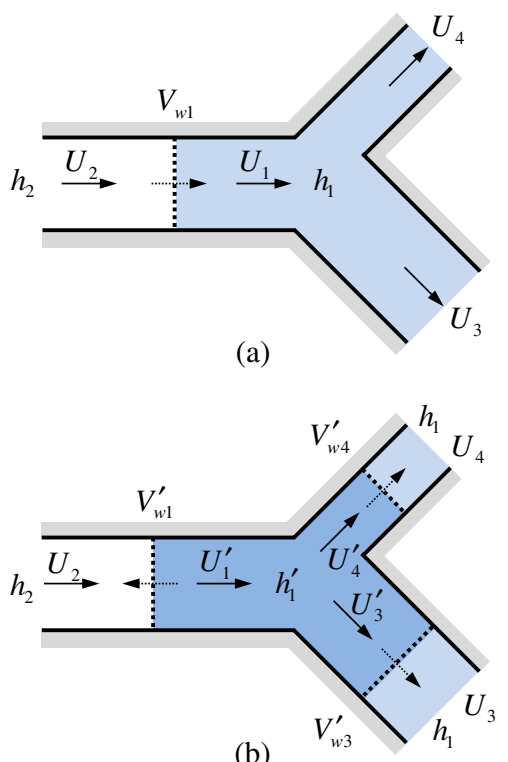

Fig. 3. Surge wave though a channel junction in initial state (a) and after reflection (b), where $V_{w}$ is absolute surge wave celerity observed by a stationary observer, $U$ mean flow velocity, and $h$ flow depth; index ' refers to postreflection conditions. For positive surge $h_{2}>h_{1}^{\prime}>h_{1}$; for negative surge $h_{2}<h_{1}^{\prime}<h_{1}$ 


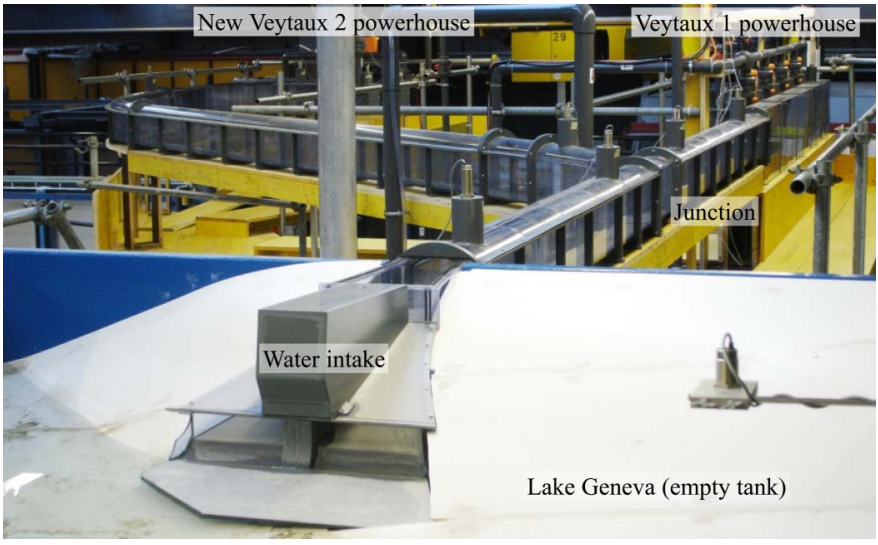

Fig. 4. Hydraulic model of downstream facilities of underground Veytaux HPP

dynamic processes caused by the inclination of the water surface. Favre (1935) proposes an explicit calculation method for surge waves that are superimposed to a uniform or gradually varied steady or unsteady base flow in prismatic configurations including friction and slope.

Surge waves are totally or partially reflected at a blind end, at a channel section enlargement or restriction, at a lake entrance, or at a channel junction. Furthermore, when two surge waves meet, one traveling from downstream, one from upstream, two new surges traveling in the reverse directions are formed. When two surges traveling in the same direction meet, they form one surge of a given height and an absolute front celerity (Favre 1935).

Reflections at dead end, channel transition, and entrance to a lake (Fig. 2) can be treated as proposed in Chow (1959). When the incoming surge height $z_{1}$ and the reflection coefficient $C_{r}$ are known, the height of the reflected surge can be defined as $z_{1}{ }^{\prime}=C_{r} \cdot z_{1}$. The reflection coefficient is a function of the transition geometry. The entrance of a surge wave into a lake is a particular case of an expansion of the section, where the velocity is assumed zero. Thus the lake water level is not affected. When a positive surge wave arrives in a channel junction (Fig. 3), the wave is partially reflected as a negative surge and two positive surges are transmitted into the two downstream reaches.
The surge wave front is followed by secondary waves, commonly called Favre waves, in relation to the first systematic work done by Favre (1935). Several other researchers have advanced the knowledge in this domain (Faure and Nahas 1961; Benet and Cunge 1971; Zairov and Listrovoy 1983; Treske 1994; Meile et al. 2013). The formation of secondary waves is described by Soares Frazao and Zech (2002) and is mainly due to nonhydrostatic pressure distribution around the wave front. Whether secondary waves or breaking of the front is observed depends on the ratio of the flow depths before $h_{1}$ and after $h_{2}$ the wave front, respectively, on the surge Froude number $\mathrm{F}_{s}$ defined as

$$
\mathrm{F}_{s}=\frac{V_{w}-U_{1}}{\sqrt{g h_{1}}}=\sqrt{\frac{h_{2}}{2 h_{1}^{2}}\left(h_{1}+h_{2}\right)}
$$

where $V_{w}=$ absolute celerity of surge wave front and $U_{1}=$ mean flow velocity of base flow. Because secondary waves have crests and troughs, $h_{2}$ is representative of the mean flow level after the wave front.

Two conditions may be necessary for the formation of secondary waves (Meile 2007). First, a fast variation of the flow depth in time is required as a result of a sudden rise in discharge, e.g., due to starting turbine operations (positive surge from upstream), or a decrease in discharge, e.g., due to a shutdown of turbine operations (negative surge from upstream). Secondly, the magnitude is related to breaking conditions of surge waves. The impact of secondary waves increases with the difference in discharge before and after the wave front until breaking conditions of the surge front are reached. The water level no longer undulates after the wave front when highly breaking conditions are achieved (Favre 1935; Henderson 1966). Experimental investigations have shown that breaking conditions are related either to the ratio of flow depths before and after the passage of the wave front (Favre 1935; Benet and Cunge 1971) or to the surge Froude number (Treske 1994).

For this study, of particular interest are experiments on positive surge waves in rectangular channels advancing upstream and their reflection at a lake entrance and channel junctions as well as the simulation of Favre waves. In addition, the combined operation of two power plants leads to a superposition of surge waves.

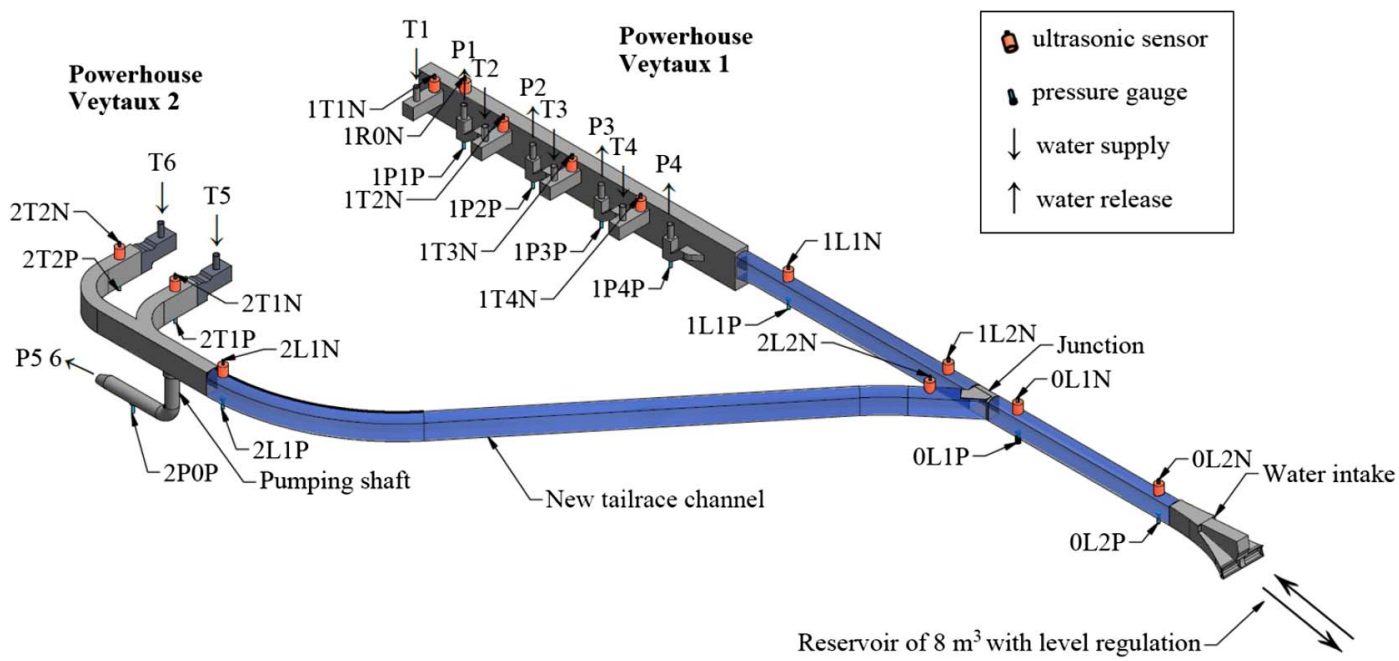

Fig. 5. Three-dimensional sketch of experimental setup of Veytaux HPP: water supply and release, position of ultrasonic sensors, and pressure gauges; an additional ultrasonic sensor measures level in tank 

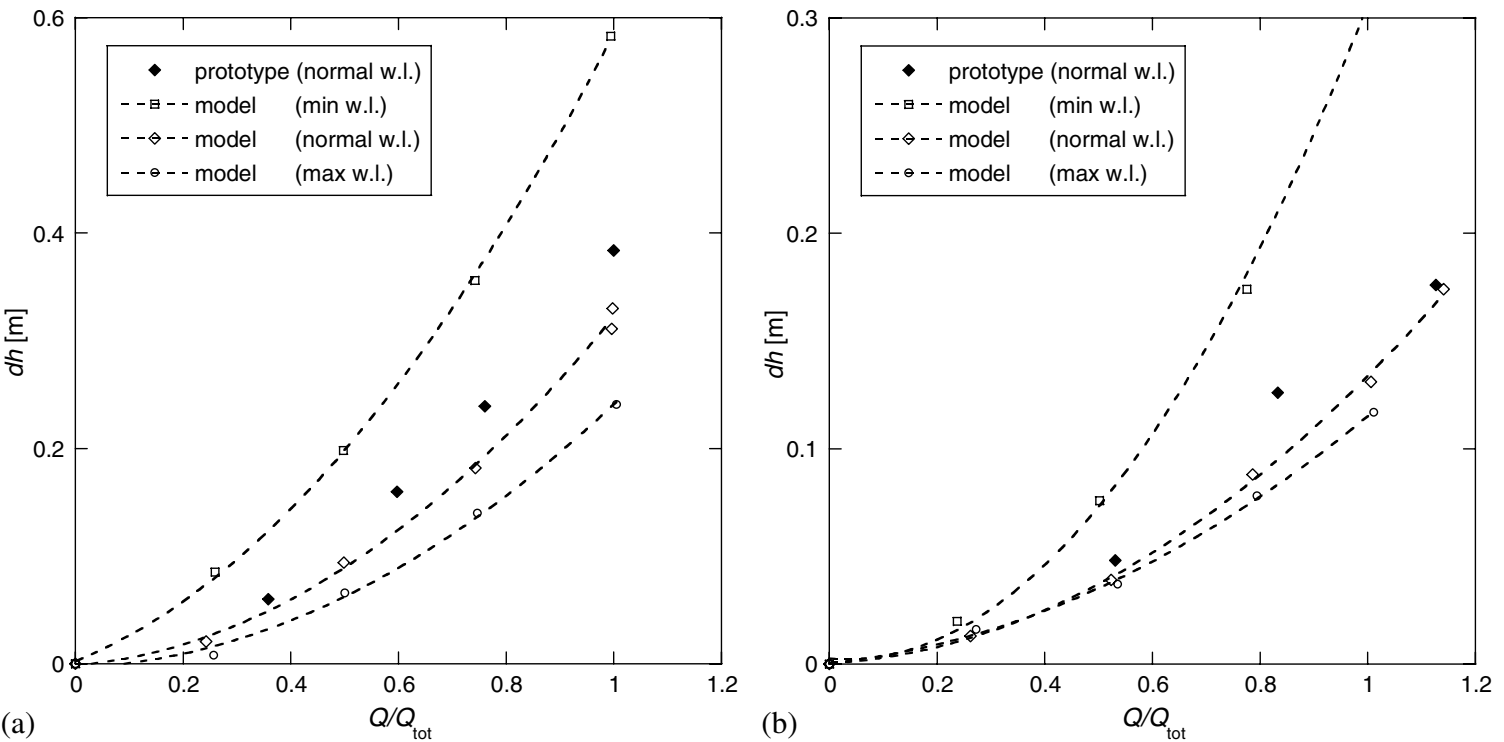

Fig. 6. Simulated head losses dh between the Veytaux 1 powerhouse and Lake Geneva for steady flow conditions when turbining (a) and pumping (b); total discharge $Q_{\text {tot }}$ is $33 \mathrm{~m}^{3} / \mathrm{s}$ for turbining and $24 \mathrm{~m}^{3} / \mathrm{s}$ for pumping; minimum water level (min w.1., $371.0 \mathrm{~m}$ (a.s.1.), normal (normal w.1., $372.2 \mathrm{~m}$ a.s.1.), and maximal (max w.1., $372.6 \mathrm{~m}$ a.s.1.) were used

\section{Experimental Setup}

To study unsteady flow behavior, a hydraulic model (Fig. 4) was built at the Laboratory of Hydraulic Constructions (LCH) of Ecole Polytechnique Fédérale de Lausanne (EFPL), in Lausanne, Switzerland. The undistorted model was operated according to the Froude similarity with a horizontal and vertical length scale ratio of $1: 30$, reproducing the existing downstream facilities of the four Veytaux 1 units with the $200 \mathrm{~m}$ long tailrace to Lake Geneva as well as the new downstream facilities of the two Veytaux 2 turbines with its new $300 \mathrm{~m}$ long tailrace channel connected to the existing one. All channels have a width of $4.3 \mathrm{~m}$. The pumps of Veytaux 2 are supplied by a pumping shaft, whose inlet structure
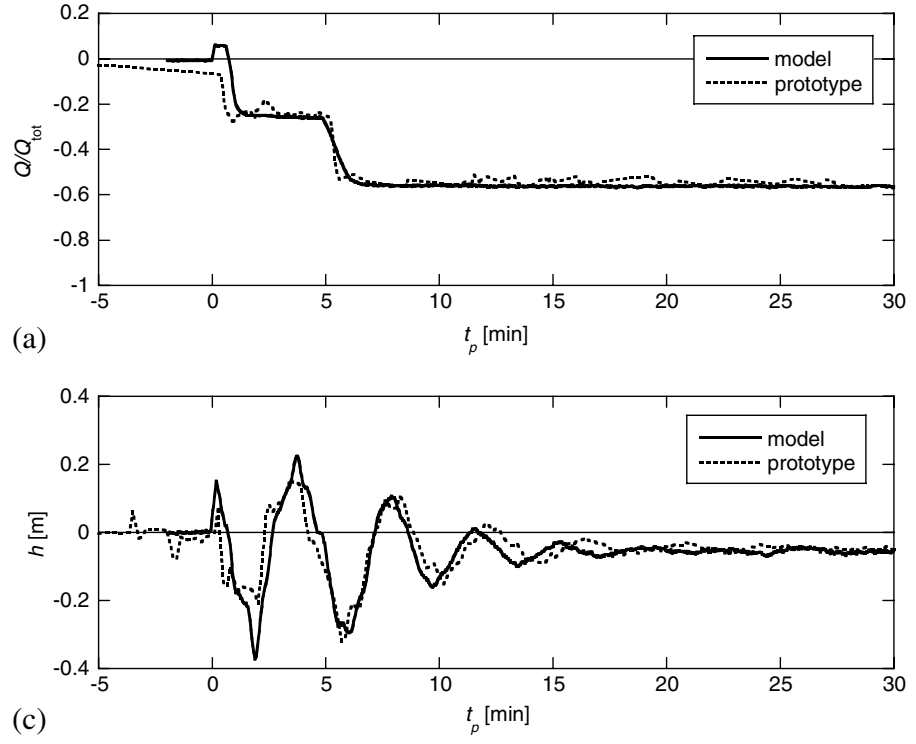

was reproduced. All hydraulic elements were built with transparent PVC. The intake area in Lake Geneva was modeled with a steel tank of $8 \mathrm{~m}^{3}(4 \times 4 \times 1 \mathrm{~m})$.

The model contained a large number of hydraulic components as well as measuring equipment (Fig. 5). Each turbine and pump system of Veytaux 1 and 2 (4 in total) was separately equipped with a pump of variable frequency and an electromagnetic flow meter with $\pm 0.5 \%$ accuracy. The discharge of all turbines (Fig. 5, T1 to T6) and pumps (Fig. 5, P1 to P4), except Pumps 5 and 6 of Veytaux 2 (P5 and P6), could be individually defined by gradually adaptable valves. The tank of the intake region in Lake Geneva was supplied by a pump and equipped with a movable weir for level definition.
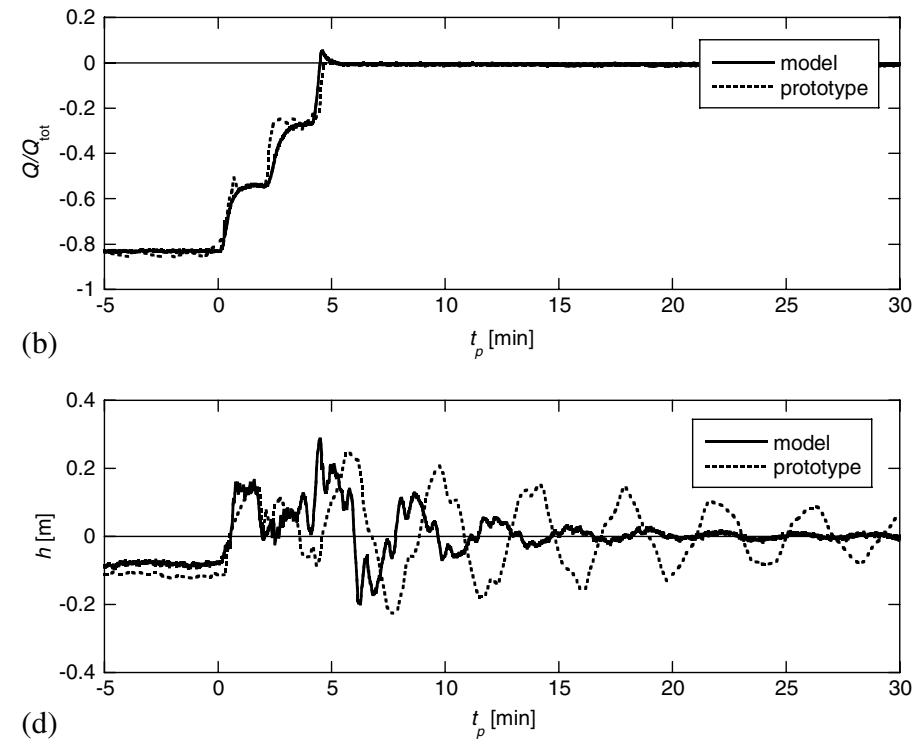

Fig. 7. Comparison of prototype and model measurements: (a) start of two pumps with measured discharge $Q$ divided by total theoretical discharge at full capacity $Q_{\text {tot }}$ of four pumps $\left(24 \mathrm{~m}^{3} / \mathrm{s}\right)$; (b) shutdown of three pumps with measured discharge $Q$ divided by total theoretical discharge at full capacity $Q_{\text {tot }}$ of four pumps ( $24 \mathrm{~m}^{3} / \mathrm{s}$ ); (c) start of two pumps with level variation in Veytaux 1 powerhouse (Sensor 1R0N) over prototype time $t_{p}$; (d) shutdown of three pumps with level variation in Veytaux 1 powerhouse (Sensor 1R0N) over prototype time $t_{p}$ 
Water levels were measured by 14 ultrasonic sensors (Fig. 5, labels ending with $\mathrm{N}$ ) and 11 pressure gauges (Fig. 5, labels ending with $\mathrm{P}$ ), both having a $50 \mathrm{~Hz}$ acquisition frequency and $\pm 0.5 \mathrm{~mm}$ accuracy. For reasons of redundancy, four tailrace positions and the two Veytaux 2 turbine chambers have additional pressure gauges. Sensor 1 R0N between Units 1 and 2 of Veytaux 1 is the only sensor also present on the prototype. The level in the tank was measured by ultrasonic sensors.

The model was operated by a LABView interface, making it possible to define discharge series, valve opening and closing times, and data acquisition.
The head losses and the waves in the common tailrace channel of the two Veytaux pumped-storage plants were also investigated using numerical three-dimensional simulations (De Cesare et al. 2014).

\section{Model Validation}

The model calibration tests were carried out with today's HPP layout. The measurements of the 1R0N sensor allowed the comparison of the model's and the prototype's head losses and water levels for the existing geometry.
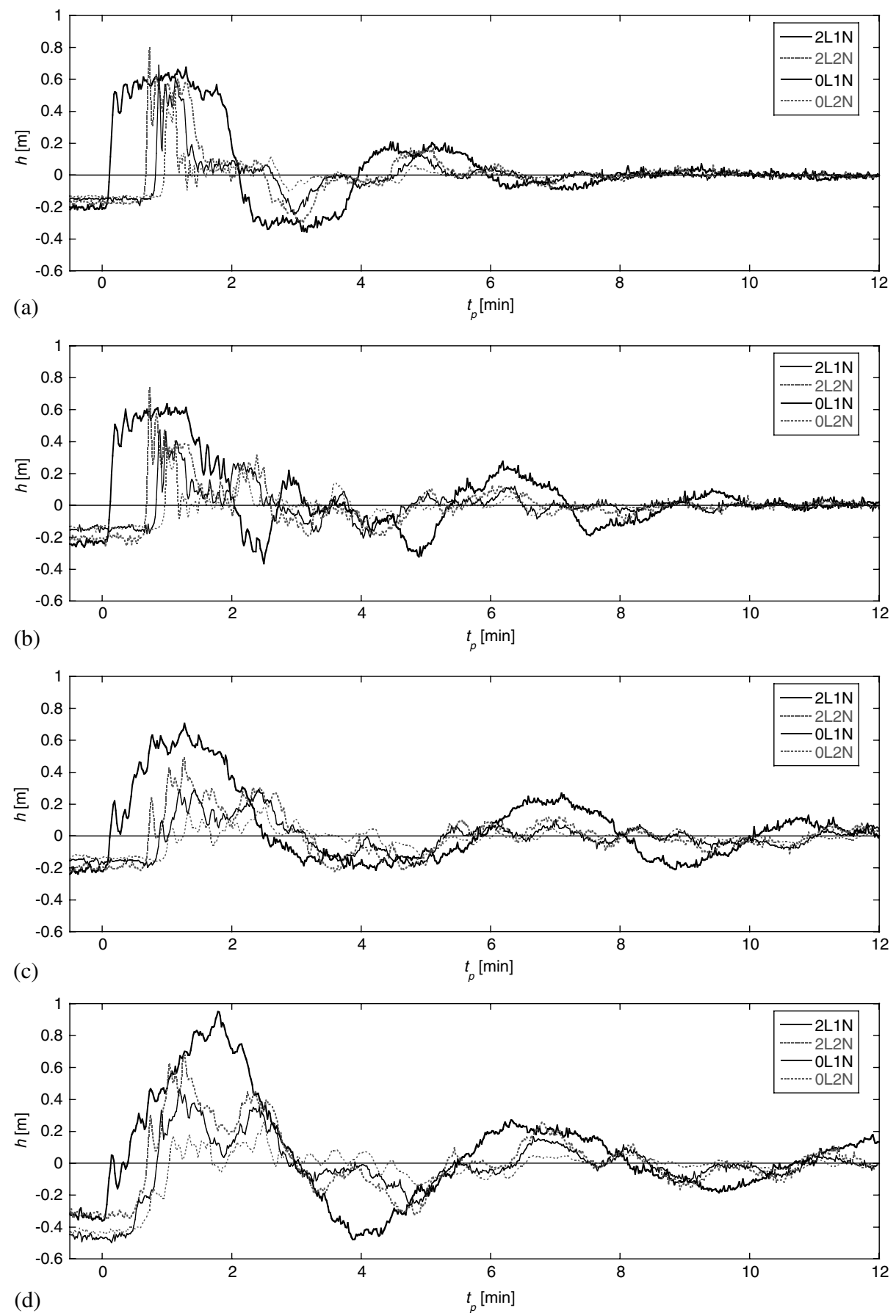

Fig. 8. Surge wave propagation in tailrace channel between Veytaux 2 powerhouse and Lake Geneva for sudden shutdown of pumps on prototype scale; shutdown of Veytaux 2 pumps with Layout A (a); shutdown of Veytaux 2 pumps with Layout B (b); shutdown of Veytaux 2 pumps with future layout (c) and shutdown of Veytaux 1 and 2 pumps with future layout (d); $t_{p}$ is the prototype time after the pump shutdown and $h$ is the water level difference between the displayed sensor and the Lake Geneva water level (constant) 


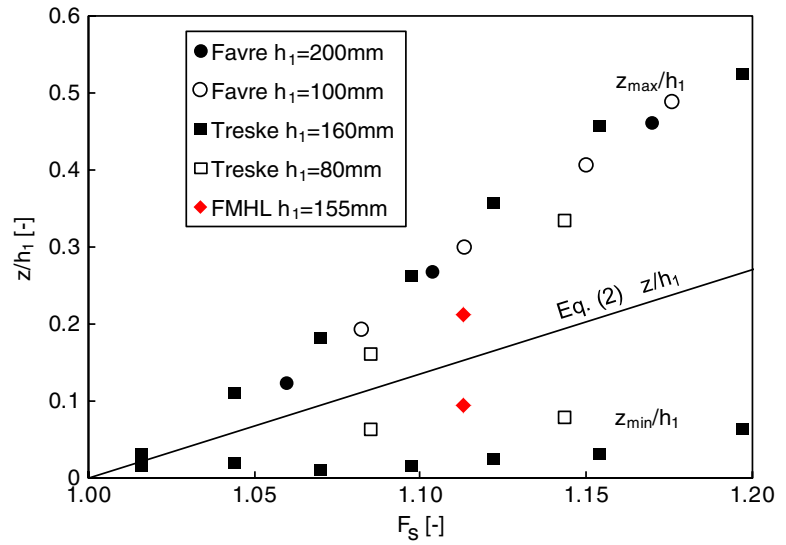

Fig. 9. Secondary wave amplitudes $z / h_{1}$ of positive surge experiments by Favre (1925) and Treske (1994), as well as for Scenario 1 of FMHL model with $2 \mathrm{~L} 2 \mathrm{~N}$ sensor; $\mathrm{F}$ is the Froude number, $z$ the surge height, $z_{\max }$ the surge height at the crest of the first Favre wave, $z_{\min }$ the surge height at the trough of the first Favre wave, and $h_{1}$ the initial depth; the surge of Scenario 1 has a lower amplitude than experiments found in the literature

In steady flow conditions, tests were conducted for minimal and maximal levels as well as average water levels of Lake Geneva. In turbining mode [Fig. 6(a)] the simulated head losses are slightly lower than measured on the prototype, meaning that the model is slightly too smooth. There is even a better agreement for pumping mode [Fig. 6(b)].

In transient flow, the level oscillation was measured during the machines' start or stop after a period of steady conditions. The startup of two pumps in the model [Fig. 7(a)] reveals similar amplitudes and slightly shorter period of water level oscillation than that of the prototype. The higher peak values in the model come from the positive discharge during the first minute when the valves are opened and the pump has not gained enough power to avoid a backward flow. There are more differences between the model and the prototype for the shutdown of three pump units [Fig. 7(b)]. Although the amplitude is similar, the period is shorter and the damping faster due to additional damping by the Lake Geneva tank.

\section{Results}

One goal of the model tests was to analyze and understand the surge wave propagation in case of an emergency shutdown of the pumps of both powerhouses. To define the impact of the structural elements on wave reflection, four scenarios were investigated using the three following different layouts:
- Layout A: only Veytaux 2 pump shaft to the lake, by blocking the Veytaux 2 turbine chamber and the Veytaux 1 tailrace channel.

- Layout B: Veytaux 1 tailrace channel and Veytaux 2 pump shaft, by blocking the Veytaux 2 turbine chamber.

- Future layout: Veytaux 1 and Veytaux 2 tailrace channels, corresponding to final design.

Scenario 1 uses Layout A with a sudden shutdown of all Veytaux 2 pumps [Fig. 8(a)]. Only the lake and the wall blocking the Veytaux 2 turbine chambers produce reflections. At the $2 \mathrm{~L} 1 \mathrm{~N}$ sensor, this creates a surge wave of approximately $0.8 \mathrm{~m}$ with secondary waves of approximately $0.12 \mathrm{~m}$. Before the junction at the $2 \mathrm{~L} 2 \mathrm{~N}$ sensor, the wave's height is slightly decreased. Favre waves of $0.3 \mathrm{~m}$ amplitude are measured. After $65 \mathrm{~s}$, the positive wave reaches the lake and is reflected as a negative one. The waves are almost damped after 8 min.

Scenario 2 is applied to Layout B with a sudden shutdown of the Veytaux 2 pumps [Fig. 8(b)]. This configuration adds a wave due to the reflection at the junction. The initial surge wave is the same as in Scenario 1, including the highest peak at $2 \mathrm{~L} 2 \mathrm{~N}$, until passing the junction after $45 \mathrm{~s}$. The junction reduces the height of the wave propagating toward the lake by $0.15-0.2 \mathrm{~m}$. The reflected negative wave from the junction passes at $2 \mathrm{~L} 1 \mathrm{~N}$ after $80 \mathrm{~s}$ and reduces the water level by approximately $0.3 \mathrm{~m}$. Favre waves of $0.3 \mathrm{~m}$ are measured. The levels are almost damped after $10 \mathrm{~min}$.

The future layout with a sudden shutdown of all Veytaux 2 pumps is investigated in Scenario 3 [Fig. 8(c)]. In this configuration, the surge from the shaft propagates in two directions, toward the lake and toward the Veytaux 2 turbine chambers. Additional reflection is added by the turbine chambers of Veytaux 2 . The bidirectional propagation raises the level more gently, but the level still reaches the same height at $2 \mathrm{~L} 1 \mathrm{~N}$. In the channel between the junction and the lake, the surge wave is lower than in the previous tests because the surge front is not as steep as for Layouts A and B and the reflection by the lake happens before the full height is reached. The negative reflections from the junction and the lake theoretically arrive at the shaft at the same moment as in the previous test but cannot be distinguished in the gradual water level drop of $2 \mathrm{~L} 1 \mathrm{~N}$. Damping of the surge takes $20 \mathrm{~min}$, which is slower than tests with Layouts $\mathrm{A}$ and $\mathrm{B}$.

In Scenario 4, the future layout is investigated with the sudden shutdown of three Veytaux 1 pumps (without Pump 4 for operating reasons on the prototype) and all Veytaux 2 pumps [Fig. 8(d)]. The initial steady water level in the channel system is lower compared to the previous tests. The higher discharge induces higher velocities and, thus, higher head losses. This leads to a slightly higher surge wave for Veytaux 2. The level variations are similar to those of the previous test until the surge wave from Veytaux 1 arrives. The superposition of the surge waves of Veytaux 1 and

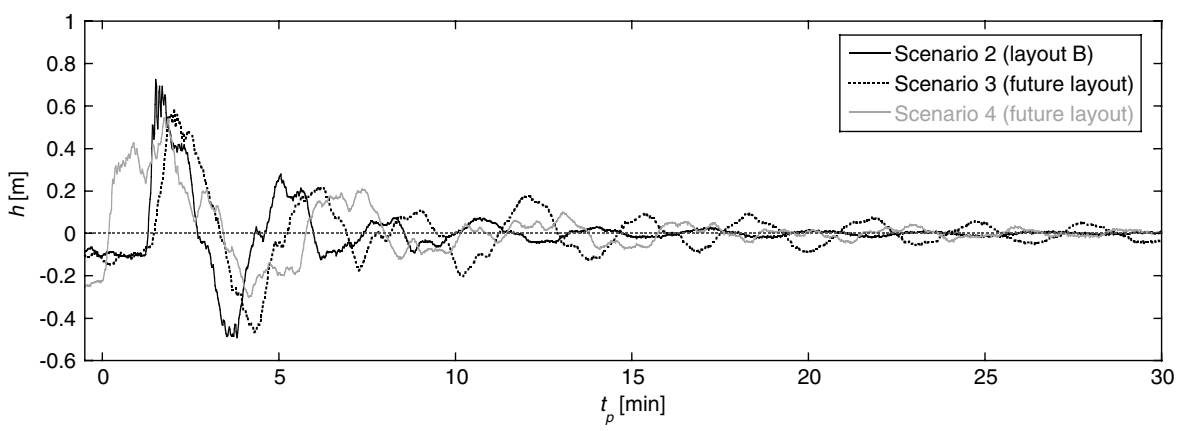

Fig. 10. Comparison of level variation $h$ in Veytaux 1 powerhouse (1R0N sensor) for Scenarios 2-4 


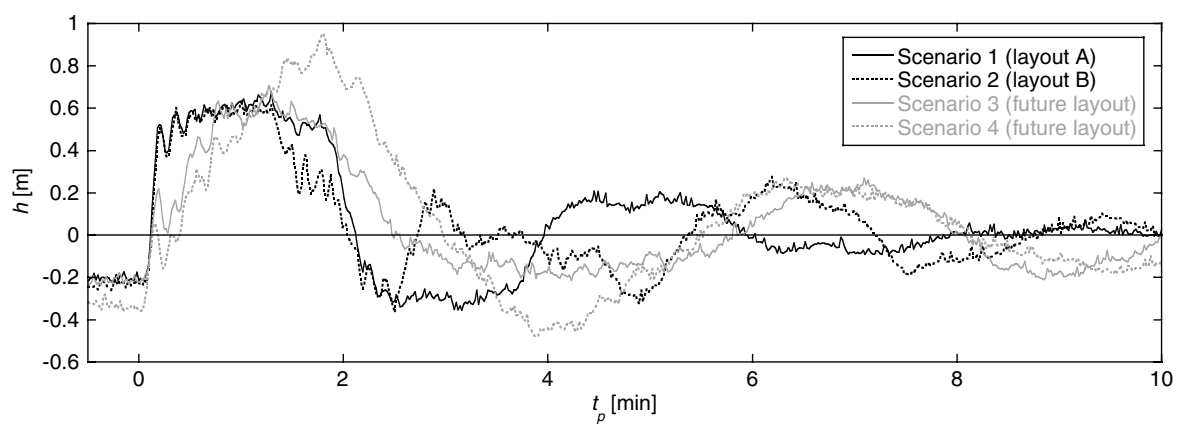

Fig. 11. Comparison of water level variation $h$ in Veytaux 2 tailrace channel (2L1N sensor) for Scenarios $1-4$

Veytaux 2 produces the maximum peak for $2 \mathrm{~L} 1 \mathrm{~N}$ for the four tests. Because of the Veytaux 1 surge, the level keeps rising in Veytaux 2 $(2 \mathrm{~L} 1 \mathrm{~N})$ after $80 \mathrm{~s}$ despite the arrival of the negative reflection of the Veytaux 2 surge from the junction. For the other sensors, the secondary waves of Scenario 1 reach higher levels. Like Scenario 3 with the final design, it takes 20 min to dampen the surges.

The tests were performed with the lake maximum water level (372.6 $\mathrm{m}$ a.s.1.), a prototype discharge of $24 \mathrm{~m}^{3} / \mathrm{s}$ for Veytaux 2 and $19 \mathrm{~m}^{3} / \mathrm{s}$ for Veytaux 1 in Scenario 4 . The water depths in the tailrace channels were between 4.6 and $4.8 \mathrm{~m}$ for Scenarios 1-3 and between 4.3 and $4.7 \mathrm{~m}$ for Scenario 4.

\section{Discussion}

Favre waves appear in Scenarios 1 and 2 but cannot be measured in the future layout (Scenarios 3 and 4). For Scenario 1 and Sensor 2L2N, secondary waves are compared to the experiments made by Treske (1994) in a straight flume (Fig. 9). Although the initial flow depth $h_{1}$ is very similar, the maximum and minimum amplitudes of the secondary waves are less than half of Treske's $160 \mathrm{~mm}$. Favre's measurements have higher maximal amplitudes as well. The difference lies in the surge formation. In Treske's experiments the waves are generated by lowering a sluice gate in a fraction of a second, whereas in the FMHL model, the surge is generated by closing a pneumatic valve at the bottom of the Veytaux 2 shaft in less than $1 \mathrm{~s}$. The surge is thus initiated on the surface above the shaft and not against a sluice wall, giving a more gradual surge front.

Regarding a reliable operation of the Veytaux 1 powerhouse for the future design, only Scenarios 3 and 4 are relevant (Fig. 10). The amplitude is quite similar whether only Veytaux 2 or both powerhouses are stopped. But the surge from the Veytaux 2 shutdown only (Scenario 3 ) needs more time to dampen, which could be a problem for sequent pumps and turbine operations. Scenario 2 generates a higher peak, showing that the Veytaux 2 turbine chambers have a positive effect by reducing the highest wave in the Veytaux 1 powerhouse.

At the $2 \mathrm{~L} 1 \mathrm{~N}$ sensor close to the Veytaux 2 powerhouse, the reflection of the Veytaux 2 surge at the junction is measured after $80 \mathrm{~s}$ and the reflection from the lake after $120 \mathrm{~s}$. The obstruction of the turbine chamber has a high impact on wave reflection (Fig. 11). In Scenario 3, the water level needs about $30 \mathrm{~s}$ longer to rise to the maximum level compared to Scenarios 1 and 2. In Scenario 4, the surge wave from Veytaux 1 reaches Veytaux 2 after $60 \mathrm{~s}$, which makes the level rise even more than in Scenario 3 despite the arrival of the negative reflection from Veytaux 2's coming from the junction at $80 \mathrm{~s}$.

The discussed scenarios comprise an emergency shutdown of the pumps at the highest water level, generating the highest level in the Veytaux 1 turbine chambers. The results show a maximum surge height of $0.59 \mathrm{~m}$. Because the Pelton turbines are $2.9 \mathrm{~m}$ above the maximum lake level, no problems should occur during operation. The most critical cases in normal conditions were also tested and do not show higher values than the emergency case. Thus no limitation or loss of flexibility for the operation of the existing Veytaux 1 turbines is expected. For the pumps, a minimum operation level of Lake Geneva was defined for the pumping with both powerhouses.

The tests show the complexity of the reflections in the future tailrace channels of the Veytaux powerhouses and the necessity to use a hydraulic model to assess it. The end walls in the powerhouses reflect surges that retain the same sign, whereas the lake and the junction reflect waves with the opposite sign.

\section{Conclusions}

The behavior of surge waves in an extended tailrace channel of a pumped-storage HPP was experimentally investigated by hydraulic modeling tests. In situ measurements allowed a calibration of the model for today's layout. The results indicate reflection, absorption, and Favre waves for an emergency shutdown of the Veytaux 2 pumps, corresponding to positive surge waves advancing upstream. The numerous reflections produce a complex pattern that cannot be investigated by calculations only, and there is no software or method to simulate Favre waves in nonrectangular channels. When such problems are encountered during design, model tests are mandatory.

The simple channel of Layout A produces a steep wave front, as in theory. Measured Favre waves are only half of the magnitude predicted by Treske (1994) because the surge emerges from a shaft and not from a sluice gate. The highest amplitude is detected for the initial wave front. The Veytaux 2 turbine chambers in the future layout help to reduce the steep surge wave front and the peak level in the Veytaux 1 powerhouse.

Investigations in steady and unsteady flow conditions led to geometry changes at the Lake Geneva intake, the common tailrace channel, and the junction to reduce the head loses. Additional modifications to the upper part of the Veytaux 2 pump shaft were needed to reduce head losses and air entrainment. For turbine operations no restrictions were required, whereas a minimum level of Lake Geneva is required for pumping at a total power of $420 \mathrm{MW}$ or more.

\section{Acknowledgments}

The authors wish to thank Cédric Bron for his significant contribution to the experimental setup. The study was funded by the Forces Motrices Hongrin-Léman (FMHL), represented by Gaël Micoulet, 
and followed by the consulting engineer consortium Stucky, Emch \& Berger, and EDF, represented by Martin Wickenhäuser (Stucky).

\section{Notation}

The following symbols are used in this paper:

$c=$ wave celerity relative to flow velocity;

$C_{r}=$ surge reflection coefficient;

$\mathrm{F}_{s}=$ surge Froude number;

$g=$ acceleration due to gravity;

$h=$ flow depth;

$Q=$ discharge (positive for turbining, negative for pumping);

$Q_{\text {tot }}=$ total discharge;

$t_{p}=$ prototype time;

$U=$ mean flow velocity;

$V_{w}=$ absolute surge wave celerity; and $z=$ surge height.

\section{References}

Benet, F., and Cunge, J. A. (1971). "Analysis of experiments on secondary undulations caused by surge waves in trapezoidal channels." J. Hydraul. Res., 9(1), 11-33.

Chow, V. T. (1959). Open-channel hydraulics, McGraw-Hill, New York.

De Cesare, G., Bieri, M. P., Terrier, S., Candolfi, S., Wickenhäuser, M., and Micoulet, G. (2014). "Flow and waves in a common tailrace channel of two pump storage plants-Phyical and numerical." Advances in Hydroinformatics, P. Gourbesville, eds., Springer.

Favre, H. (1935). Etude théorique et expérimentale des ondes de translation dans les canaux découverts, Dunod, Paris.

Faure, J., and Nahas, N. (1961). "Etude numérique et expérimental d'intumescences à forte courbure du front." La Houille Blanche, 5, 576-587.

Henderson, F. M. (1966). Open channel flow, Macmillan, New York.

Meile, T. (2007). Influence of macro-roughness of walls on steady and unsteady flow in a channel, communication $\mathrm{LCH} \mathrm{N}^{\circ} 36$, A. Schleiss, ed., Ecole polytechnique fédérale, Lausanne, Switzerland.

Meile, T., Boillat, J.-L., and Schleiss, A. J. (2011). "Water-surface oscillations in channels with axi-symmetric cavities." J. Hydraul. Res., 49(1), 73-81.

Meile, T., Boillat, J.-L., and Schleiss, A. J. (2013). "Propagation of surge waves in channels with large-scale bank roughness." J. Hydraul. Res., 51(2), 195-202.

Soares Frazao, S., and Zech, Y. (2002). "Undular bores and secondary waves-Experiments and hybrid finite-volume modelling." J. Hydraul. Res., 40(1), 33-43.

Swiss Federal Office of Energy (SFOE). (2008). "Bestimmung von Wirkungsgraden bei Pumpspeicherung in Wasserkraftanlagen.” Bern, Switzerland.

SFOE. (2011). "Statistik der Wasserkraftanlagen der Schweiz." Bern, Switzerland.

Treske, A. (1994). "Undular bores (Favre-waves) in open channelsExperimental studies.” J. Hydraul. Res., 32(3), 355-370.

Zairov, K. I., and Listrovoy, P. P. (1983). "Experimental investigation of the positive traveling surges fore-part observed in canals." Proc., 20th International Association for Hydraulic Research (IAHR) Congress, 210-218. 